\title{
Catolicismo e poder no Congo: o papel dos intermediários nativos, séculos XVI a XVIII
}

Marina de Mello e Souza*

Resumo: Ao incorporar formas de exercício do catolicismo ao modo de vida local, tornando-o um importante elemento na afirmação de hierarquias de poder, os dirigentes do Congo passaram a conviver com missionários e recorreram à escrita e à religião para se relacionarem com os novos agentes que passaram a atuar em suas terras a partir do final do século XV, especialmente a Coroa portuguesa e a Igreja Católica, com sede em Roma. Os sacerdotes e catequistas nativos, formados pelas escolas dos missionários em terras conguesas e angolanas, ou mesmo em Lisboa, foram centrais na estruturação de novas práticas e crenças que aliavam elementos cristãos aos tradicionais da região. Tomamos como exemplo disso um determinado sacerdote: D. Calixto Zelotes dos Reis Magos, sobre o qual temos informações esparsas, mas sabemos que teve papel de destaque em algumas situações da política local.

Palavras-chave: Congo cristão. Sacerdotes congueses. Poderes locais.

\section{Introdução}

Existem algumas situações de encontros culturais que são especialmente ricas para o estudo de processos de transformação de sistemas simbólicos, necessários para que as pessoas em contato, pertencentes a universos diferentes, criem um campo comum de compreensão que permita a convivência. A maneira como a elite dirigente do Congo recebeu a presença portuguesa em seu território a

\footnotetext{
*Departamento de História - FFLCH - USP. Núcleo de Apoio à Pesquisa Brasil África - PRP - USP. Contato: marinamsouza@usp.br.
}

Anos 90, Porto Alegre, v. 21, n. 40, p. 51-63, dez. 2014 
Catolicismo e poder no Congo: o papel dos intermediários...

partir do final do século XV, numa relação que se estendeu por cinco séculos, é uma dessas situações, e por isso mesmo já foi bastante abordada por uma gama diversa de estudiosos. (HILTON, 1985; THORNTON, 1981; 1984; 2013; MACGAFFEY, 1994)

Nos primeiros contatos entre portugueses e congueses, tudo indica que o catolicismo foi o principal meio de comunicação entre os diferentes universos culturais. Para os portugueses, a sua disseminação era parte importante do movimento que os lançava à conquista de terras distantes, ao lado dos interesses comerciais. Para as elites conguesas, serviu para a afirmação de uma facção política frente a outras e, a médio prazo, para a consolidação de poderes centralizados. Imediatamente identificado como uma forma dos homens se comunicarem com a esfera espiritual, alguns dos seus ritos foram aceitos pelos governantes locais. Isso foi entendido pelos portugueses como uma conversão ao catolicismo e uma vitória, amplamente alardeada pela Coroa e pela Igreja lusitanas, que chamavam para si a responsabilidade de trazer para o seio do catolicismo o maior número possível de pessoas, especialmente as que eram contatadas como resultado da expansão marítima.

Falando línguas completamente diferentes, assim como eram suas culturas, a ajuda de intérpretes foi fundamental nos primeiros contatos, assim como nos subsequentes, que se sucederam por séculos. O batismo dos primeiros chefes ocorreu em 1491, por ocasião da terceira viagem dos portugueses àquela região, sendo que, em viagem anterior, em 1485, alguns congueses haviam sido levados para Lisboa, onde conheceram o modo de vida lusitano e aprenderam o português. ${ }^{1}$ A partir de então, inaugurou-se um tempo de relações estreitas entre o Congo e Portugal, nas quais elementos da sociedade portuguesa foram adotados pelos congueses. A adoção de ritos e objetos do culto católico, resultante da ação de missionários, e de símbolos de poder, como títulos e insígnias da nobreza portuguesa, sugeridos por regimentos e embaixadas enviadas no início do século XVI por D. Manuel, rei de Portugal, deu-se por meio de processos de ressignificação levados a cabo pelos congueses, em diferentes momentos de sua história. ${ }^{2}$ Nesse processo, foram centrais as pessoas que estavam em contato direto com os missionários, comerciantes e funcionários reais, pertencentes principalmente aos grupos dirigentes

Anos 90, Porto Alegre, v. 21, n. 40, p. 51-63, dez. 2014 
locais. Aqui nós nos deteremos numa categoria específica dessas pessoas, ligada a uma área central tanto das sociedades ibéricas quanto das centro-africanas, qual seja, a religião.

\section{Religião e poder}

No início da Idade Moderna, quando os portugueses e congueses primeiro entraram em contato, a religião perpassava todos os aspectos da vida, não somente dos centro-africanos como também dos europeus. A política era atividade diretamente conectada às forças espirituais, e assim como os monarcas europeus eram ungidos ou abençoados pelos representantes da Igreja ao assumirem o poder, também os chefes africanos, considerados elos especiais de ligação com o mundo invisível, estreitamente conectado com a vida presente, eram legitimados por cerimônias conduzidas pelos sacerdotes. Portanto, em uma situação na qual diferentes poderes políticos entravam em contato, a religião assumiu necessariamente lugar de destaque. Nesse contexto, o catolicismo tornou-se importante meio de aproximação entre Portugal e o Congo, que incorporou elementos da religião dos brancos como forma de lidar com as novas situações criadas pela presença desses estrangeiros. ${ }^{3}$ No processo de incorporação de elementos do catolicismo, foi central o papel dos intérpretes, mestres e catequistas nativos que, educados nas escolas abertas pelos missionários a partir do início do século XVII, ou enviados para Lisboa desde o início século XVI, traduziram para os termos de sua cultura e sua língua os ensinamentos a que foram expostos.

Nos processos de ensinamento do catolicismo a pessoas do lugar, que exigiam a tradução de conceitos, os missionários recorreram a palavras nativas para buscar nas culturas que eram alvo da catequese ideias equivalentes às que queriam ensinar. Assim, chamaram a igreja de mbila (local onde os chefes eram enterrados), o padre católico de nganga (uma dada categoria de especialistas religiosos) e Deus de Nzambi (entidade criadora de todas as coisas e inatingível). Além de tornar o catolicismo elemento componente da sua religião, os chefes congueses passaram a usar títulos da nobreza portuguesa para reafirmar as hierarquias e legitimar os seus poderes do campo

Anos 90, Porto Alegre, v. 21, n. 40, p. 51-63, dez. 2014 
Catolicismo e poder no Congo: o papel dos intermediários...

social e político. Seguindo sugestão de orientações mandadas pelo monarca português por meio de embaixadas, os manis acrescentaram aos títulos que já tinham os de reis, príncipes e condes, além de adotar junto com o batismo católico nomes portugueses precedidos de Dom ou Dona. Os dois procedimentos serviram para consolidar maneiras particulares de receber os ensinamentos cristãos e incorporar fórmulas de poder dos portugueses. Esses processos inseriam as contribuições vindas dos portugueses nos quadros de pensamento locais mais do que os transformavam de fato. Foram maneiras de traduzir e incorporar elementos da sociedade lusitana que serviram para as populações locais lidarem, conforme suas próprias escolhas, com as situações novas criadas pela presença de estrangeiros, que chegaram para ficar por muito tempo e provocaram mudanças de amplo alcance na vida das pessoas e formas de organização locais.

O domínio da leitura e da escrita também tornou-se um importante distintivo social, estando a educação da elite, especialmente dos filhos dos principais chefes, a cargo de missionários católicos. Além de catecismos em quicongo, foram escritas uma quantidade significativa de cartas em português, assinadas pelos chefes e seus secretários, que constituem um corpo documental excepcional para a reconstituição da história do Congo, especialmente dos séculos XVI e XVII. Como as sociedades africanas de então não possuíam escrita, a adoção da escrita em português pela elite dirigente do Congo em sua relação com a Coroa portuguesa e com a Igreja Católica constituem fato absolutamente excepcional, que favorece a realização de estudos sobre essa região e esse período.

Frisamos, entretanto, que a adoção de elementos e comportamentos das sociedades europeias se deu a partir dos padrões locais e das necessidades criadas pelas situações novas com as quais os congueses passaram a conviver, as quais provocaram mudanças em suas formas de organização. Mas estas continuaram a seguir padrões próprios: o catolicismo, ou o que então passou a ser entendido como tal, tornou-se religião dos chefes e fator de fortalecimento do poder central e de manutenção da unidade política e territorial, sempre ameaçada pela tendência à autonomia dos poderes locais, principalmente depois que estes passaram a se fortalecer com o contato direto com os europeus que chegavam pela costa atlântica,

Anos 90, Porto Alegre, v. 21, n. 40, p. 51-63, dez. 2014 
oferecendo novas mercadorias e possibilidades de alianças. $\mathrm{O}$ batismo e os ritos católicos, como a missa, o casamento e o enterro, passaram a indicar pertencimento à elite dirigente, que mantinha contato mais estreito com os estrangeiros brancos. A utilização do nome católico, sempre precedido de Dom ou Dona, tornou-se mais um título entre os muitos que eram acumulados vida afora por aqueles a quem isso era acessível, que então, além dos títulos e nomes nativos, passaram a portar os nomes católicos. A partir do governo de D. Afonso I (Mbemba Nzinga, que governou de 1507 a 1542), o principal introdutor do catolicismo no Congo e responsável pela inauguração de uma nova era no que diz respeito à sua organização política, os principais chefes passaram a ser conhecidos pelos seus nomes católicos e apareceram linhagens com nomes extremamente poéticos, como os Água Rosada e os Lágrimas de Cristo.

Um sacerdote nativo cuja existência foi registrada por diversas fontes tinha o fantástico nome de D. Calisto Zelotes dos Reis Magos. Seu nome e seus títulos nativos não foram registrados. Mas as pistas deixadas por muitas fontes permitem que reconstituamos parte significativa de sua vida, exemplar do papel ocupado por pessoas pertencentes aos grupos dirigentes locais que receberam educação religiosa e formal em escolas dos missionários católicos, os quais se tornaram peças-chaves na propagação de ensinamentos e práticas religiosas percebidas como católicas e indispensáveis às relações políticas, e mesmo econômicas, constituídas a partir do contato com os europeus.

\section{Um intérprete cultural}

Educado nos moldes portugueses, sabia latim, lia, falava e escrevia bem o português, bem como tinha prática em instruir os neófitos. Provavelmente educado pelos jesuítas em seu colégio em mbanza Congo, é identificado como "sacerdote preto" possivelmente filho de "[...] D. Calisto Andorinha Zelotes dos Reis Magos, fidalgo congolês, morto na batalha de Bumbi em 18/12/1622." " Observando-o por meio das poucas e esparsas referências localizadas, ele parece mais um dos mestres treinados em mbanza Congo, pelos

Anos 90, Porto Alegre, v. 21, n. 40, p. 51-63, dez. 2014 
Catolicismo e poder no Congo: o papel dos intermediários...

missionários, para ajudarem em sua missão e servirem de intérpretes, mas deve ter sido ordenado, pois é chamado de padre secular por Cavazzi, que viveu na região de 1654 a $1667 . .^{5}$

D. Calixto Zelotes dos Reis Magos aparece em alguns relatos e documentos que chegaram até nós e se destaca não só pelo seu nome extraordinário, mas também por episódios da sua vida. Ao descrever práticas mágicas dos congueses, Cavazzi conta um episódio para ilustrar como “[...] entre esses pretos há sempre exemplos de rara justiça, especialmente entre aqueles que costumam lidar com europeus [...]", que lhe foi narrado "[...] por um certo Pe Calisto Zelotes, intérprete dos nossos missionários durante muitos anos". (CAVAZZI DE MONTECÚCCOLO, vol. I, 1965, p. 112). Ao final do episódio narrado, que gira em torno da aplicação de ordálios, o "rei do Micocco" (Macoco, Tio, Anzico), localizado a nordeste do Congo, convenceu-se da falsidade dos sacerdotes locais e pediu aos missionários que fossem catequizá-lo e batizá-lo. (CAVAZZI DE MONTECÚCCOLO, vol. I, 1965, p. 113). Nessa e em outras ocasiões, percebemos que Calisto Zelotes servia de ponte entre dois universos mentais, fazendo traduções em ambas as direções, como deviam fazer todos os mestres, catequistas e padres ordenados entre aqueles que frequentavam as escolas das missões.

Em 1648, D. Calisto Zelotes estava em viagem entre os dembos, pois havia sido designado pelo mani Congo D. Garcia II (Nkanga Lukeni, que governou de 1641 a 1661) intérprete dos missionários capuchinhos Boaventura de Corella e Francisco de Veas na missão a Oando, chefatura subordinada ao Congo. Ali acabaram todos prisioneiros em um ataque liderado por Ginga Mona, o principal chefe guerreiro de Matamba, à época governada por Nzinga.

Após permitir que os capuchinhos retornassem ao Congo, inclusive tornando-os portadores de uma carta sua ao papa, Nzinga exigiu que Calisto Zelotes permanecesse junto a ela, atribuiu-lhe importantes funções ligadas à sua vida cotidiana e religiosa, e o fez seu conselheiro, principal secretário e confessor. Antonio de Gaeta, missionário capuchinho que teve um importante papel junto a Nzinga, qualificou-o como "o favorito da rainha e também intérprete da missão”. (GAETA; GIOIA, 1669, p. 223). Quando, em 1660, Cavazzi substituiu Antonio de Gaeta na missão na mbanza,

Anos 90, Porto Alegre, v. 21, n. 40, p. 51-63, dez. 2014 
ou kilombo, de Nzinga, encontrou Calisto Zelotes ocupando o lugar de seu principal secretário. Foi também por essa época que chegou uma carta da "Sagrada Congregação", endereçada aos missionários de Matamba, que insistia para que fosse construído um seminário "onde jovens pretos" aprendessem a ler, escrever e "outras ciências necessárias ao estado clerical", para que pudessem transmitir os ensinamentos católicos "sem o auxílio dos missionários estrangeiros" (CAVAZZI DE MONTECÚCCOLO, vol. II, 1965, p. 134). Em seu comentário a esta a recomendação, Cavazzi disse que era necessário esperar melhor momento, pois só algumas pessoas adultas e mais dóceis eram capazes de aprender as orações e principais noções que na Europa "[...] até as crianças facilmente aprendem [...]", e acrescentou que na cidade de São Salvador (mbanza Congo, de onde o mani Congo administrava seu território), "[...] havia já uma escola com quarenta rapazes" (CAVAZZI DE MONTECÚCCOLO, vol. II, 1965, p. 135).

Os quarenta rapazes deveriam estar sendo treinados para auxiliarem os missionários, aprendendo a escrita e a leitura, as rezas e discutindo passagens dos livros sagrados. Quanto aos impedimentos que Cavazzi mencionou existirem para a criação de novos seminários, podemos imaginar que fossem, além da oposição de sacerdotes locais, relativos ao que era considerado a extrema inconstância da conversão, pois a manutenção das práticas religiosas tradicionais, mesmo por aqueles que recebiam o batismo, frequentavam as missas e aceitavam o matrimônio católico, era sempre criticada nos relatos dos missionários. Para garantir a conversão verdadeira, defendiam a queima dos ídolos, destruição dos altares, expulsão dos "feiticeiros" e separação entre os convertidos ao catolicismo e os não conversos, para diminuir as chances de recaída daqueles nas práticas tradicionais. No que diz respeito ao bom ministério da fé entre os centro-africanos, o capuchinho respondeu às recomendações da Propaganda Fide dizendo que, no que dependesse dos missionários, tudo fariam, mas alertava para a grande resistência de muitos em abandonar as crenças tradicionais, principalmente alguns conselheiros dos chefes, que não aceitavam o catolicismo e criticavam os missionários mesmo quando suas pregações e práticas eram acolhidas. 
Catolicismo e poder no Congo: o papel dos intermediários...

Não era esse o caso de D. Calisto Zelotes dos Reis Magos. Mesmo esparsas, as informações sobre ele nos contam que pertencia à elite local e foi educado no colégio dos jesuítas, no qual eram formados catequistas, intérpretes e sacerdotes nativos que auxiliavam os missionários em suas andanças pelo território e garantiam a disseminação e manutenção do catolicismo na região. Nessas expedições, desempenhava o papel de intérprete, não só auxiliando a comunicação verbal entre os missionários europeus e os moradores das aldeias, mas também traduzindo os significados das práticas tradicionais para os missionários. Por outro lado, quando traduzia os ensinamentos cristãos para os nativos, deveria recorrer a noções, imagens e ideias que pudessem ser por eles compreendidas, contribuindo para a elaboração de uma forma particular de entender os ensinamentos católicos.

Além de atuar nos territórios diretamente controlados pelo Congo, D. Calisto Zelotes foi peça importante na aproximação de Nzinga com o catolicismo. Chefe de Matamba, ora aliada ora inimiga do mani Congo, ela aceitou missionários em sua mbanza e adotou elementos do catolicismo quando, enfraquecida pela idade e perda do apoio que teve dos holandeses enquanto eles ocuparam pontos estratégicos da costa atlântica na região de Luanda, aceitou a paz e as relações comerciais com os portugueses.

Portanto, D. Calisto Zelotes é exemplo de uma categoria de intermediários importantes na introdução de transformações nas sociedades locais que as aparelharam para as situações novas desencadeadas pela presença de europeus na região, interessados em comerciar, catequisar e ocupar territórios. Quando exerceu esse papel, elementos do catolicismo já haviam sido adotados pelos chefes e introduzidos nos ritos e nas relações de poder há mais de 150 anos, sendo que, desde os primeiros tempos de contato, houve um empenho dos grupos dirigentes do Congo em tomar em suas próprias mãos o controle sobre os ritos católicos que adotaram. Veículo de aproximação dos governantes congueses com os portugueses, o catolicismo, por outro lado, serviu para afirmar a autonomia dos chefes, que se relacionavam diretamente com Roma e assim garantiam sua independência política frente a Portugal. A existência de sacerdotes católicos nativos também era fator de fortalecimento

Anos 90, Porto Alegre, v. 21, n. 40, p. 51-63, dez. 2014 
da independência do Congo, pois, uma vez que tinham importantes funções na legitimação dos poderes locais, a independência na esfera religiosa de Portugal, ou Roma, garantia que fosse melhor controlada pelos chefes congueses.

\section{Considerações finais: o catolicismo e a unidade do Congo}

Os catequistas e sacerdotes nativos, que sustentaram a continuidade das práticas introduzidas pelos missionários católicos, como batismos, missas, penitências, casamentos e funerais, nas quais rezas, cruzes, imagens de santos e procissões substituíram ou foram acrescentadas às práticas e aos objetos tradicionalmente utilizados, foram figuras centrais na organização do poder dos chefes quando as estruturas políticas então vigentes entraram em colapso e houve uma tendência à descentralização do poder central, a partir da segunda metade do século XVII. Em 1665, os congueses sofreram uma derrota arrasadora em batalha travada contra os portugueses, em Ambuíla, quando foram mortos o mani Congo e os principais chefes que poderiam assumir o poder central.

Depois de um longo período de guerras nas quais diferentes linhagens disputaram a primazia pelo governo de um território convulsionado pelo tráfico de escravos, pela pressão dos comerciantes atlânticos e pelo ímpeto de conquista territorial dos portugueses, a unidade política do Congo e a manutenção de sua autonomia foram em grande parte permitidas pelos laços simbólicos elaborados a partir de elementos do catolicismo, religião à qual os principais chefes haviam aderido, à sua moda. Os ritos católicos, ou as suas variantes locais, e a atribuição do hábito da Ordem de Cristo, direito concedido pelos reis portugueses aos mani Congo, foram fundamentais na manutenção de vínculos políticos entre regiões cuja administração cotidiana era completamente autônoma. ${ }^{6}$ Ao longo do século XVIII, quando a presença de missionários europeus era rara, foram os sacerdotes nativos, reconhecidos ou não como tais pela Igreja Católica, que mantiveram vivas as formas locais de exercício do catolicismo. A dependência que os poucos missionários que nessa época atuaram na região tinham desses mestres e sacerdotes nativos era ainda maior

Anos 90, Porto Alegre, v. 21, n. 40, p. 51-63, dez. 2014 
Catolicismo e poder no Congo: o papel dos intermediários...

do que em tempos anteriores, quando já era indispensável sua ajuda. A catequese dos missionários europeus só era aceita se houvesse sua adequação às normas locais, estabelecidas a partir da atuação dos mestres nativos, como pode ser depreendido por passagens do relato de Rafael Castelo de Vide, que atuou no Congo no final da década de 1780 e que mostra a sua preocupação relativa à aprovação de sua conduta pelos mestres e intérpretes nativos. ${ }^{7}$

Essa situação extremamente peculiar pode ser entendida, segundo a ótica da ortodoxia católica e dos interesses da Coroa portuguesa, como um fracasso da missão catequética à medida que a adoção do catolicismo se deu pela via do desenvolvimento de formas adaptadas dessa religião e não resultou em seu controle pela Igreja Católica, pois, especialmente no século XVIII, eram os sacerdotes locais que estavam à frente dos ritos e dos ensinamentos. Mas, pela ótica dos caminhos percorridos pelos grupos sociais nos processos de intercâmbio, pode ser entendida como uma bem sucedida tradução das propostas lusitanas aos códigos locais, à medida que foram selecionados alguns elementos dentre o conjunto de novidades oferecido de forma a que as populações locais, e em especial seus governantes, fossem capazes de adquirir instrumentos para lidar com as novas situações criadas pelos contatos ao mesmo tempo que mantinham a sua autonomia frente aos estrangeiros, e mesmo reforçavam suas as posições de mando.

Se os chefes congueses tiveram a habilidade de reverter em seu proveito situações que a princípio visavam à sua submissão frente aos portugueses, fossem eles comerciantes, missionários ou funcionários reais, estes e os representantes da Igreja Católica também foram hábeis ao se adaptarem às circunstâncias locais, deixando de cumprir normas básicas da sua sociedade, como a que interditava a ordenação de sacerdotes católicos que apresentassem sangue impuro, ou seja, ascendência judia, ameríndia ou africana. Ao miscigenarem-se com as populações locais e adaptarem suas normas para as diferentes circunstâncias, os portugueses foram capazes de construir um império, a despeito da exiguidade de seus recursos materiais e demográficos. Pois se não controlaram o Congo enquanto este se transformou para conviver autonomamente com os que vieram de fora do continente e ali lentamente se enraizaram, souberam construir

Anos 90, Porto Alegre, v. 21, n. 40, p. 51-63, dez. 2014 
sociedades mestiças a partir das quais construíram as bases de uma real dominação, econômica e política, que daria fôlego a um império que do Oriente se voltou para a América e desta para a África, da qual foram os últimos colonizadores a se retirar.

\section{CATHOLICISM AND POWER AT KONGO: THE ROLE OF THE LOCAL PRIESTS, $16^{\mathrm{TH}}$ TO $18^{\mathrm{TH}}$ CENTURIES}

Abstract: While incorporating Catholic rituals and believes at the local life and turning them important for the consolidation of hierarchical structures of power, the Kongo chiefs begun to share their life with missionáries and looked after the religion and written words to maintain a relationship with the new people who begun to have business at their land since the end of the $15^{\text {th }}$ century, especially speaking the Portuguese officials and the emissaries from the Catholic Church and the Vatican. The native priests and catechists educated at the missionary schools at Kongo and Angola, or even at Lisbon, were fundamental for the structuration of new practices and believes resultant from mixed elements from Christianity and local traditional religion. As an example of that situation we present here a specific priest: D. Calixto Zelotes dos Reis Magos, about whom we have some sparse information and who had a key role in some local political events.

Keywords: Christian Kongo. Kongolese priests. Local powers.

\section{Notas}

${ }^{1}$ A principal fonte para esse momento inaugural de uma nova fase na história do Congo é o relato de Rui de Pina, feito a partir do depoimento de Rui de Souza, capitão da expedição portuguesa de 1491. Ver RADULET, 1992.

${ }^{2}$ Exemplos de trabalhos que analisam os processos de ressignificação de ritos e objetos católicos incorporados pelos congueses são: Fromont (2011) e Souza (2009). ${ }^{3} \mathrm{O}$ argumento de que o catolicismo serviu para os congueses lidarem com as transformações trazidas pela presença dos portugueses em seu território, conforme a lógica local, delineada por Craemer, Vansina e Fox (1976), segundo a qual situações novas pediam novas formas de lidar com elas, é desenvolvido por Wyatt MacGaffey (1994) e aceita por vários estudiosos, entre os quais me incluo. ${ }^{4}$ Nota de Leguzzano, baseado em António Cadornega, História das Guerras Angolanas, 1680, em CAVAZZI DE MONTECÚCCOLO (1965 [1687], vol. II, p. 394). 
${ }^{5}$ Ao falar sobre a missão de Bamba, fundada junto com várias outras em 1648, Leguzzano, na nota 155, vol. I, p. 347 da obra de CAVAZZI DE MONTECÚCCOLO, diz que ela foi designada aos Pe Boaventura de Sardenha e Pe Calisto Zelotes "sacerdote indígena", conforme consta em António de Teruel, Descripción Narrativa (1664). O comentador de CADORNEGA (1972), José Matias Delgado, também diz que Calisto Zelotes era "padre secular", na nota 32 do tomo II, p. 499.

${ }^{6}$ Essa situação foi percebida por Jan Vansina, em Kingdoms of the Savanna (1966), e por Susan H. Broadhead, em Beyond decline: the Kingdom of the Kongo in the eigthteenth and nineteenth-centuries (1979).

${ }^{7}$ Rafael Castelo da Vide. Viagem e missão no Congo. Academia das Ciêncais de Lisboa. MS Vermelho 296, Rafael Castelo de Vide, 73 apud SAPEDE, 2012, p. 134.

\section{Referências}

BROADHEAD, S. H. Beyond decline: the Kingdom of the Kongo in the eighteenth and nineteenth-centuries. International Journal of African Historical Studies, n. 12, p. 615-650, 1979.

CADORNEGA, A. de O. História das Guerras Angolanas, 1680. 3 vols. Anotado e corrigido por José Matias Delgado. Lisboa: Agência Geral do Ultramar, 1972.

CAVAZZI DE MONTECUCCOLO, J. A. Descrição bistórica dos três reinos do Congo, Matamba e Angola. Tradução, notas e índice pelo Pe Graciano Maria de Leguzzano. Lisboa: Junta de Investigação do Ultramar, 1965 (1687).

CRAEMER, Willy de; VANSINA, Jan; FOX, Renée. Religious movements in Central Africa: a theoretical study. Comparative Studies in Society and History, v. 18, n. 4, p. 458-475, oct. 1976.

FROMONT, C. Under the sign of the cross in the kingdom of Kongo: Religious convertion and visual correlation in early modern Central Africa. Anthropology and Aesthetics, n. 59-60, Spring-Autumn 2011, p. 109-123.

GAETA, A. da; GIOIA, F. M. La maravigliosa conversione alla santa fede di Cristo della regina Singa, e del suo regno di Matamba nell'Africa Meridionale. Descrita com histórico stile dal P.F. Francesco Maria Gioia da Napoli. Napoli: Giacinto Pássaro, 1669.

HILTON, A. The Kingdom of Kongo. Oxford: Oxford University Press, 1985.

MACGAFFEY, W. Dialogues of the deaf: Europeans on the Atlantic coast of Africa. In: SCHWARTZ, S. (Ed.). Implicit Understandings. Observing, Reporting, and Reflecting on the Encounters Between Europeans and Other People in Early Modern Era. Cambridge: Cambridge University Press, 1994, p. 249-267. 
RADULET, C. M. A relação de Rui de Pina e a "Relação do reino do Congo". Lisboa, Comissão Nacional para as Comemorações dos Descobrimentos Portugueses, Imprensa Nacional/Casa da Moeda, 1992.

SAPEDE, T. C. Muana Congo, Muana Nzambi Ampungu. Poder e Catolicismo no reino do Congo pós-restauração (1769-1795). Dissertação (mestrado), Programa de Pós-Graduação em História Social, FFLCH, USP, 2012. (no prelo: São Paulo: Alameda e FAPESP)

SOUZA, M. de M. e. Crucifixos centro-africanos: um estudo sobre traduções simbólicas. In: ALGRANTI, Leila Mezan; MEGIANI, Ana Paula Torres (Orgs.). O Império por escrito: Formas de transmissão da cultura letrada no mundo ibérico, séculos XVI-XIX. São Paulo: Alameda, 2009. p. 333-354.

THORNTON, John K. Early Kongo-Portuguese relations: a new interpretation. In: HENIGE, David (Org.). History in Africa. A Journal of Method. Massachussetts: Brandeis University, African Studies Association, v. 8, 1981. p. 183-204. . The development of an African Catholic Church in the Kingdom of Kongo, 1491-1750. Journal of African History, n. 25, 1984. p.147-167.

Afro-Christian Syncretism in the Kingdom of Kongo. The Journal of African History, v. 54, issue 1, March 2013, p. 53-77.

VANSINA, Jan. Kingdoms of the Savanna. Madison: The University of Wisconsin Press, 1966.

Autora convidada. 